๑

\title{
Fixed combination of repaglinide and metformin in the management of type 2 diabetes
}

This article was published in the following Dove Press journal:

Diabetes, Metabolic Syndrome and Obesity:Targets and Therapy 19 June 2009

Number of times this article has been viewed

\section{Robert Moses \\ Clinical Trials and Research Unit, South East Sydney and Illawarra Area Health Service, New South Wales, Australia}

\begin{abstract}
Treatment to target fasting blood glucose $(\mathrm{FBG})$, postprandial glucose $(\mathrm{PPG})$ and $\mathrm{HbA}_{1 \mathrm{c}}$ are essential in the management of type 2 diabetes to reduce the risk of vascular complications. Early combination therapy with oral agents is increasingly being seen as important to achieve this. Repaglinide, a rapid-acting insulin secretagogue, targets PPG, and metformin, an insulin sensitizer, targets FBG. Because of their complementary modes of action these therapies are frequently given as combination therapy in separate tablets. To overcome the issues with adherence to multiple tablets, repaglinide and metformin are now available in a fixed-dose combination (FDC). Repaglinide/metformin FDC is bioequivalent to each tablet given separately, suggesting that the efficacy and safety profile is similar. There is no effect of food on repaglinide when in the FDC. Repaglinide/metformin FDC is as effective in reducing $\mathrm{HbA}_{\mathrm{lc}}$ and FBG whether given twice or three times daily, with a similar safety profile. Repaglinide/metformin FDC twice daily is as effective in reducing $\mathrm{HbA}_{1 \mathrm{c}}$ and $\mathrm{FBG}$ as rosiglitazone/metformin FDC with a similar safety profile, but unlike the rosiglitazone/metformin FDC, repaglinide/metformin FDC improves the lipid profile. Repaglinide/metformin FDC represents a new option in the pursuit of achieving glucose targets and reducing vascular risk in type 2 diabetes, with the advantage of improving adherence.
\end{abstract}

Keywords: type 2 diabetes, metformin, repaglinide, fixed-dose combination

\section{Introduction}

\section{Management issues in diabetes}

Type 2 diabetes is characterized by defects both in insulin secretion from the beta cells and in insulin sensitivity, leading to hyperglycemia and the resulting increased risk of microvascular and macrovascular complications. To reduce the risk of these vascular complications, intensive treatment to target fasting blood glucose (FBG) concentrations, postprandial glucose (PPG) concentrations and glycosylated hemoglobin $\left(\mathrm{HbA}_{1 \mathrm{c}}\right)$ levels is a key goal in the management of patients with type 2 diabetes.

The response of the beta cell after a meal in people with type 2 diabetes is in two phases: the first phase 0 to 10 minutes after a meal, followed by a steady and more prolonged second phase. The loss of the first phase is a key determinant of postprandial hyperglycemia and is characteristic both of impaired glucose tolerance and type 2 diabetes. ${ }^{1}$ While $\mathrm{HbA}_{1 \mathrm{c}}$ is the accepted measure of glucose control over time, Monnier and colleagues have shown that the relative contribution of postprandial hyperglycemia to overall hyperglycemia varies with $\mathrm{HbA}_{1 \mathrm{c}}$ levels. $^{2}$ Postprandial hyperglycemia is the main contributor to overall daily hyperglycemia in people with mild or moderate 
hyperglycemia, whereas fasting hyperglycemia is the main contributor in people whose diabetes is more poorly controlled. Specifically, the role of fasting hyperglycemia becomes most important when $\mathrm{HbA}_{1 \mathrm{c}}$ rises above $8.4 \%$; as control of hyperglycemia improves with treatment, the role of PPG therefore becomes more important. ${ }^{2}$ Given the importance of both PPG and FBG to overall hyperglycemia it is rational to target both PPG and FBG concentrations when treating hyperglycemia in type 2 diabetes.

Evidence for the effects of intensive treatment on vascular outcomes comes from the United Kingdom Prospective Diabetes Study (UKPDS); initial results from this study showed that intensive treatment resulted in a decreased risk of microvascular, but not macrovascular complications. ${ }^{3}$ However, during the 10 years of follow up of the UKPDS there were continued risk reductions for microvascular events in the intensively treated group compared with the conventionally treated group and the risk reductions for myocardial infarction became significantly different between groups (despite a loss of glycemic differences between groups). ${ }^{4}$ Furthermore, a prospective observational analysis of the UKPDS showed that each $1 \%$ reduction in mean $\mathrm{HbA}_{1 \mathrm{c}}$ was associated with risk reductions of $21 \%$ for any endpoint related to diabetes, $21 \%$ for deaths related to diabetes, $14 \%$ for myocardial infarction and $37 \%$ for microvascular complications. ${ }^{5}$ However, there are some recent data that contradict the UKPDS data. The Action to Control Cardiovascular Risk in Diabetes (ACCORD) trial was stopped early because of an increased death rate in the intensive control group $\left(\mathrm{HbA}_{1 \mathrm{c}}\right.$ target of $<6.0 \%$ ) compared with the standard therapy group $\left(\mathrm{HbA}_{1 \mathrm{c}}\right.$ target of $7.0 \%$ to $7.9 \%) .{ }^{6}$ While no apparent increase in mortality was found in the Action in Diabetes and Vascular Disease: Preterax and Diamicron Modified Release Controlled Evaluation (ADVANCE) trial, intensive therapy (mean $\mathrm{HbA}_{1 \mathrm{c}}$ of $6.5 \%$ over 5 years) did not significantly reduce the risk of major macrovascular events compared with standard therapy (mean $\mathrm{HbA}_{1 \mathrm{c}}$ of $7.3 \%$ over 5 years), but nephropathy was significantly reduced in the intensive treatment group. ${ }^{7}$ Similarly, the Veteran Affairs Diabetes Trial (VADT) detected no difference in macrovascular or microvascular complication rates between patients treated intensively (median $\mathrm{HbA}_{1 \mathrm{c}}$ of $6.9 \%$ over 5.6 years) or those receiving standard treatment (median $\mathrm{HbA}_{1 \mathrm{c}}$ of $8.4 \%$ over 5.6 years). ${ }^{8}$

Despite the recent data from ACCORD, ADVANCE and VADT, a joint statement from the American College of Cardiology, American Diabetes Association (ADA) and American Heart Association reassures clinicians that, because of the other significant evidence for the benefits of reducing
$\mathrm{HbA}_{1 \mathrm{c}}$, clinicians should continue to reduce $\mathrm{HbA}_{1 \mathrm{c}}$ to targets of below 7.0\%, except for certain specific situations. ${ }^{9}$

Another observation from the UKPDS was that treatment with metformin decreases the risk of any diabetes-related endpoints, diabetes-related mortality and all-cause mortality in overweight people with type 2 diabetes compared with conventional treatment (primarily diet), sulfonylureas or insulin. ${ }^{10}$ These findings were consistent throughout 10 years of follow up. ${ }^{4}$ UKPDS also showed that people treated with sulphonlyureas, who had metformin added early in the course of their treatment, had an increased risk of diabetesrelated death, compared with sulfonylureas alone. ${ }^{10}$ Rao and colleagues carried out a meta-analysis of this and other studies (some with similar findings and others with conflicting findings) and found that the combination of sulfonylureas and metformin significantly increased the relative risk of the composite endpoint of cardiovascular hospitalization or mortality, but that this combination had no effect on either CVD mortality or all-cause mortality alone. ${ }^{11}$ The authors suggested that the increased risk may stem from: the association of sulfonylureas with weight gain; the potential for sulfonylureas to cause hypoglycemia and the potential for the addition of metformin to impair recovery from hypoglycemia (which may increase ischemia and arrhythmias); or the fact that patients who need this combination may have a more aggressive form of the disease. ${ }^{11}$ Nevertheless, because intensive glucose control with metformin decreases the risk of diabetes-related endpoints in overweight people with diabetes, and is associated with less weight gain and fewer hypoglycemic attacks than insulin and sulfonylureas, metformin has become a first-line pharmacological therapy for people with type 2 diabetes.

\section{Combination therapy in type 2 diabetes}

Traditionally, the first step in the management of people with type 2 diabetes was to provide advice on lifestyle changes to reduce hyperglycemia, and when these ceased to be effective the recommended approach to drug therapy was stepwise: starting with oral monotherapy, progressing to combination dual and triple therapy, and eventually to insulin. However, in acknowledgment of the limited long-term success of lifestyle changes alone and the need for intensive therapy, a recent consensus statement from the European Association for the Study of Diabetes (EASD) and the ADA recommended that metformin should be introduced at the same time as lifestyle measures. ${ }^{12}$

Earlier treatment with combination therapies that target both FBG and PPG is also increasingly being adopted as an approach, because monotherapy frequently fails. ADA/ 
EASD recommend that when glucose concentrations are high $\left(\mathrm{HbA}_{1 \mathrm{c}}>8.5 \%\right)$, classes of drugs with greater and more rapid glucose-lowering effects are used, or that combination therapy is initiated early. ${ }^{12}$

Studies suggest that fixed-dose combinations (FDC) may have a positive effect on concordance and glycemic control. In one observational study there were no significant differences in adherence rates among newly treated patients receiving monotherapy, combination therapy, or FDC therapy; however, in patients who had previously been treated with glibenclamide or metformin and who required the addition of a second agent, adherence rates were significantly lower in those who added in a second agent than in those who switched to FDC therapy. Patients already receiving combination therapy who were switched to FDC therapy also had a significant improvement in adherence after the switch. ${ }^{13}$ A retrospective study of a FDC of metformin and glibenclamide showed that patients with type 2 diabetes receiving the FDC had a significantly greater reduction in $\mathrm{HbA}_{1 \mathrm{c}}$ than those on glibenclamide co-administered with metformin, especially when baseline $\mathrm{HbA}_{1 \mathrm{c}}$ was $\geq 8 \%$. While patients were more concordant with the FDC, regression analysis indicated that concordance was not a significant predictor of change in $\mathrm{HbA}_{1 \mathrm{c}}{ }^{14}$

Repaglinide, a rapid-acting insulin secretagogue, and metformin, an insulin sensitizer, are now available in a FDC (repaglinide/metformin FDC); the evidence supporting the use of this combination in the management of type 2 diabetes is reviewed here.

\section{Repaglinide and metformin combination therapy \\ Repaglinide}

In animal studies, a mechanism of action for repaglinide has been postulated. It appears that repaglinide stimulates insulin secretion, in the presence of glucose, by binding to sites on ATP-dependent potassium channels in the beta cell, resulting in closure of the potassium channels, beta cell depolarization, opening of calcium channels, increased calcium ion flux and upregulation of insulin secretion (Figure 1). ${ }^{15,16}$ While potassium channels are also the target for sulfonylureas, repaglinide is structurally distinct from the sulfonylureas but with some chemical resemblance to the nonsulfonylurea moiety of the molecule of the sulfonylurea glibenclamide. Repaglinide causes insulin secretion only when glucose is present, which reduces the chance of insulin secretion when blood glucose concentrations are very low. ${ }^{17}$ Sulphonylureas, on the other hand, can cause insulin secretion even when there is no glucose present, increasing the chance of hypoglycemia.

Peak plasma levels of repaglinide occur within 1 hour of oral intake and, when taken with a meal, repaglinide results

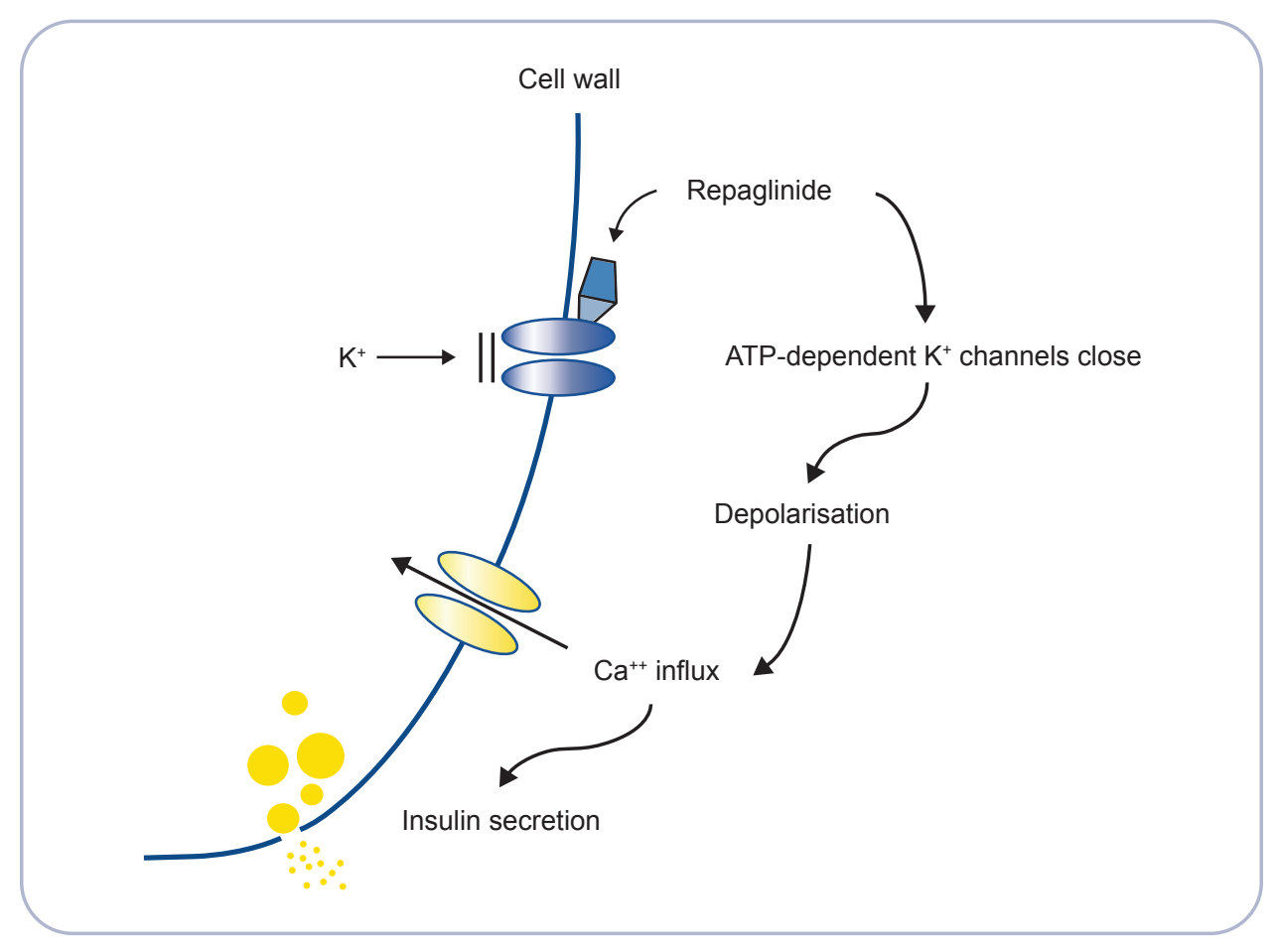

Figure I Mode of action of repaglinide. Adapted with permission from Wolffenbuttel BH. Repaglinide - a new compound for the treatment of patients with type 2 diabetes. Neth J Med. 1999;55(5):229-234. ${ }^{16}$ Copyright (C) 1999 Elsevier. 
in an early first phase rise in insulin levels, which specifically targets postprandial hyperglycemia. ${ }^{16}$ Repaglinide is rapidly eliminated, with a half-life of approximately 1 hour after either single, or multiple oral doses in people with, and without, type 2 diabetes. ${ }^{16}$ Because repaglinide is rapidly and completely absorbed from the gastrointestinal tract it is used in a meal-related dosing regimen, which reflects the physiological response to food. ${ }^{16}$ Repaglinide promotes insulin secretion only in the presence of glucose, which may reduce the likelihood of insulin secretion when blood glucose levels are very low - in theory this may therefore reduce the incidence of hypoglycemia. ${ }^{17}$ It has been shown that people who are taking repaglinide are less likely to develop symptoms of hypoglycemia if they miss or postpone a meal in comparison with those taking sulfonylureas. ${ }^{18}$

Repaglinide is at least as effective as sulfonylureas in reducing $\mathrm{HbA}_{1 \mathrm{c}}$ and $\mathrm{FBG},{ }^{16,19,20}$ with reductions in $\mathrm{HbA}_{1 \mathrm{c}}$ of up to $2.3 \%$ after 10 weeks' treatment in patients who have not previously been treated with oral agents. ${ }^{21}$ Repaglinide also decreases PPG to at least the same extent as sulfonylureas. ${ }^{20}$ The reduction in $\mathrm{HbA}_{1 \mathrm{c}}$ is significantly greater with repaglinide compared with the meglitinide nateglinide. ${ }^{22,23}$

The risk of weight gain with repaglinide is similar to the risk with sulfonylureas, ${ }^{16,19,20}$ repaglinide may cause less weight gain in people not previously treated with oral agents. ${ }^{19}$ Repaglinide has also been shown to improve homeostasis model assessment of insulin resistance (HOMA-IR) and beta cell function indexes measured by HOMA-beta. ${ }^{22}$

\section{Metformin}

Metformin is an insulin sensitizer that acts by inhibiting hepatic glucose output, increasing peripheral glucose uptake and utilization, and thus lowering FBG concentrations. ${ }^{24}$ In clinical trials, metformin has been shown to reduce $\mathrm{HbA}_{1 \mathrm{c}}$ and FBG significantly more than placebo and to the same extent as sulfonylureas, ${ }^{25}$ and to lower PPG concentrations. ${ }^{26}$

Although metformin is generally well tolerated, some patients report gastrointestinal adverse effects, which can be reduced by starting treatment at a low dose and slowly titrating upwards. Treatment with metformin is not associated with hypoglycemia, and results in weight stability or moderate weight loss, ${ }^{25,27}$ which is of particular benefit in people with type 2 diabetes who are often overweight.

\section{Rationale for combination of repaglinide with metformin}

As discussed above, a rational approach to the management of type 2 diabetes is to target both FBG and PPG concentrations. Metformin, by virtue of its action of decreasing liver glucose production and increasing glucose uptake in peripheral tissues, reduces FBG; repaglinide, by targeting the ATPdependent calcium channel in the beta cells, increases insulin production (Figure 2). The two therapeutic agents therefore have a complementary effect. Furthermore, repaglinide in combination with metformin has been shown to significantly enhance the insulin secretion index (a measure of the glucose clearance rate per unit serum insulin concentration), suggesting a synergistic effect of the two molecules on insulin sensitivity. ${ }^{28}$

Existing clinical evidence supports the use of these two agents in combination therapy. The combination of repaglinide and metformin taken as separate tablets has already been established as providing greater reductions in $\mathrm{HbA}_{1 \mathrm{c}}$ and FPG values compared with either tablet alone. ${ }^{29}$

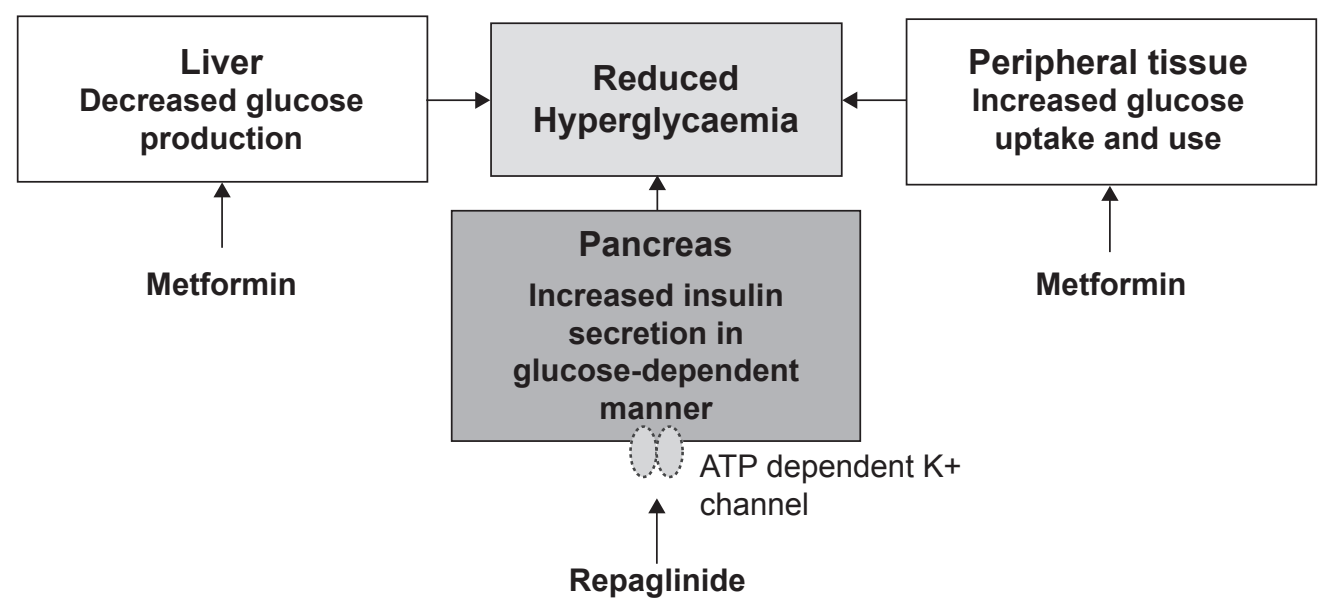

Figure 2 Complementary mode of actions of repaglinide and metformin. Raskin P. Oral combination therapy: repaglinide plus metformin for treatment of type 2 diabetes. Diabetes Obes Metab. 2008; 10(I2): I 167-I 177.43 Copyright (C) 2008 John Wiley \& Sons. Reproduced with permission of Blackwell Publishing Ltd. 
A recent re-analysis of data from this study showed that more than $56 \%$ of patients receiving combination therapy achieved a target $\mathrm{HbA}_{1 \mathrm{c}}$ of $<7 \%$ compared with $19 \%$ in both monotherapy groups. ${ }^{30}$ In a second study investigating $\mathrm{HbA}_{1 \mathrm{c}}$ targets with combination therapy in patients with previously poor glycemic control, a higher proportion of those given repaglinide plus metformin reached the target $\mathrm{HbA}_{1 \mathrm{c}}$ of $<7 \%$ than those given repaglinide alone ( $71 \%$ vs $48 \%){ }^{31}$

In a study comparing the combination of repaglinide and metformin, with the combination of nateglinide and metformin, the repaglinide combination resulted in greater reductions in $\mathrm{HbA}_{1 \mathrm{c}}(1.28 \%$ for repaglinide; $0.67 \%$ for nateglinide $)$ and FBG (39 mmol/L for repaglinide; $21 \mathrm{mmol} / \mathrm{L}$ for nateglinide) than the nateglinide combination. ${ }^{32}$

These data have led to the widespread co-administration of repaglinide and metformin as separate formulations to patients with type 2 diabetes. The combination of the two treatments may allow patients who experience side effects with metformin to reduce the dose of metformin without a loss of glycemic control. However, a single combination therapy tablet would offer increased patient convenience and the subsequent potential for increased therapy adherence. A fixed-dose, single tablet combination of these two drugs has now been assessed in clinical trials, and the pharmacokinetic, efficacy and safety data of this FDC are the focus of the remainder of this review paper.

\section{Pharmacokinetics of repaglinidel metformin FDC}

The pharmacokinetics of repaglinide/metformin FDC have been investigated in two studies - one to compare the bioequivalence of the FDC formulation with that of each component-drug administered individually, and the second to compare the pharmacokinetics of the FDC in the fed and fasted state.

The bioequivalence study was a randomized, singleblind, three-period crossover study. ${ }^{33}$ Ninety-three healthy volunteers were randomized to receive either an FDC tablet of repaglinide/metformin $2 \mathrm{mg} / 500 \mathrm{mg}$, an FDC tablet of repaglinide/metformin $1 \mathrm{mg} / 500 \mathrm{mg}$, or repaglinide $2 \mathrm{mg}$ and metformin $500 \mathrm{mg}$ co-administered as separate formulations, before a high-fat meal, in one of six possible treatment sequences. Both repaglinide and metformin in the combination tablet were bioequivalent to the individual tablets of repaglinide $2 \mathrm{mg}$ and metformin $500 \mathrm{mg}$ as measured by AUC and $\mathrm{C}_{\max }$. The FDC tablet of repaglinide/metformin $2 \mathrm{mg} / 500 \mathrm{mg}$ was dose proportional to the FDC tablet of repaglinide/metformin $1 \mathrm{mg} / 500 \mathrm{mg}$ for $\mathrm{AUC}$ and $\mathrm{C}_{\max }$.
There were no unexpected safety concerns in those treated with repaglinide/metformin FDC tablet therapy, and there were no withdrawals due to adverse events. ${ }^{33}$

The finding that both therapies in the FDC were bioequivalent to each therapy administered separately suggests that the FDC would have a similar safety and efficacy profile to repaglinide and metformin administered separately.

The study to compare the pharmacokinetics of repaglinide/metformin FDC under fasting and fed conditions was a randomized, single-blind, four-period, crossover study. ${ }^{34}$ Sixty-two healthy volunteers were randomized to one of four possible sequences and received a single dose of study medication per treatment period, either: an FDC tablet of repaglinide/metformin $2 \mathrm{mg} / 850 \mathrm{mg}$ under fasted and fed conditions (high-fat breakfast); repaglinide $2 \mathrm{mg}$ (fasted conditions); or metformin $850 \mathrm{mg}$ (fasted conditions). In the fasted state the FDC was bioequivalent to $850 \mathrm{mg}$ metformin and it was bioequivalent to repaglinide $2 \mathrm{mg}$ measured by area under the curve (AUC) but not $\mathrm{C}_{\max }$. In people who had eaten a meal the AUC for metformin with the FDC was $15 \%$ to $24 \%$ lower and $\mathrm{C}_{\max }$ was $17 \%$ to $28 \%$ lower than under fasting conditions. For repaglinide in the FDC, $\mathrm{C}_{\max }$ was $15 \%$ to $44 \%$ higher in people who had eaten a meal than under fasting conditions but the AUC showed bioequivalence between the two states. ${ }^{34}$ The results of this study suggest that there was no food effect on total repaglinide exposure in the FDC.

\section{Efficacy and safety of repaglinide/ metformin FDC \\ Comparison of repaglinide/metformin FDC twice daily and three times daily}

The efficacy and safety of repaglinide/metformin FDC was investigated in a three-arm, 26-week, open label trial. ${ }^{35-38}$ Patients with type 2 diabetes, diagnosed for at least 3 months with $\mathrm{FBG} \leq 260 \mathrm{mg} / \mathrm{dL}$, previously treated with either monotherapy or dual therapy, were randomized to receive either repaglinide/metformin FDC twice daily, repaglinide/ metformin FDC three times daily or rosiglitazone/metformin FDC twice daily. $\mathrm{HbA}_{1 \mathrm{c}}$ ranged from $7.5 \%$ to $11 \%$ for those previously on monotherapy and from $7 \%$ to $10 \%$ for those previously on dual therapy.

One of the primary objectives of the trial was to compare the efficacy, measured by reduction in $\mathrm{HbA}_{1 \mathrm{c}}$, of repaglinide/ metformin FDC twice daily with repaglinide/metformin FDC three times daily. ${ }^{35}$ Repaglinide/metformin FDC twice daily was found to be non-inferior to repaglinide/ metformin FDC three times daily in terms of reduction in 
$\mathrm{HbA}_{1 \mathrm{c}}$ (Table 1). No significant difference was seen in the number of patients reaching target $\mathrm{HbA}_{1 \mathrm{c}}$ of either $6.5 \%$ or $7.0 \%$ (Figure 3).

The investigators also carried out a subset analysis, comparing those who had previously been treated with oral monotherapy with those on dual therapy. ${ }^{37}$ The reduction in $\mathrm{HbA}_{\mathrm{lc}}$ was greatest in patients who had previously been on monotherapy, but the difference was not significant, most likely because of less advanced disease in patients on monotherapy, who therefore probably had more residual beta cell function than those on dual therapy. More patients who had been on monotherapy achieved $\mathrm{HbA}_{1 \mathrm{c}}$ targets, and significantly more patients in the three times daily group previously on monotherapy reached the target of $7.0 \%$ than those previously on monotherapy in the twice daily group (Figure 3). FBG was reduced in both treatment groups and the reduction in FBG was greater in patients who were previously on monotherapy in both treatment groups (Table 1). Most lipid parameters decreased slightly from baseline but there were no significant differences between treatment groups.

Patients on the twice daily regimen gained weight $(0.48 \mathrm{~kg})$, whereas those on the three times daily regimen lost weight $(0.33 \mathrm{~kg} ; \mathrm{p}=0.033)$, but the difference was small and not clinically relevant. ${ }^{35}$ When this was analyzed by previous therapy, patients who had previously been on monotherapy had modest weight gain, whereas those previously on dual therapy lost weight in both treatment groups.

The types and frequencies of adverse events were comparable between groups. No major hypoglycemic episodes were reported and rates of minor hypoglycemia were similar. In the subset analysis, minor hypoglycemia rates were slightly higher in patients who were previously on monotherapy, compared with those on dual therapy. ${ }^{37}$

Overall, the safety and efficacy of the twice daily regimen is similar to the three times daily regimen repaglinide/ metformin FDC, whether patients were previously on monotherapy or dual therapy.

\section{Comparison of repaglinide/metformin FDC with rosiglitazone/metformin FDC}

Another primary objective of the three-arm, 26-week, open-label trial described above was to compare the glycemic control measured by reduction in $\mathrm{HbA}_{1 \mathrm{c}}$ in patients treated with repaglinide/metformin FDC twice daily with rosiglitazone/ metformin FDC twice daily. Patients on repaglinide/metformin FDC twice daily had a reduction in $\mathrm{HbA}_{1 \mathrm{c}}$ of $0.95 \%$; those on rosiglitazone/metformin FDC twice daily had a reduction of $0.98 \%$ (Table 2). ${ }^{36}$ The difference was not significant, leading to the conclusion that treatment with repaglinide/metformin FDC twice daily was non-inferior to rosiglitazone/metformin FDC twice daily.

In the subset analysis ${ }^{38}$ the reduction in $\mathrm{HbA}_{1 \mathrm{c}}$ was greater in patients who had previously been on monotherapy than those who had been on dual therapy, but differences were non-significant (Table 2). Again, this is likely to be a result of greater residual beta cell function in patients who were previously on monotherapy.

There were no significant differences between treatment groups in the numbers of patients achieving target $\mathrm{HbA}_{1 \mathrm{c}}$ of either $6.5 \%$ or $7.0 \%$ (Figure 4 ).

The reduction in FBG was significantly higher in patients treated with rosiglitazone/metformin FDC twice daily,

Table I Changes in $\mathrm{HbA}_{\mathrm{Ic}}$, FBG, weight and rate of minor hypoglycemia in patients on repaglinide/metformin FDC twice daily (monotherapy and dual therapy) and repaglinide/metformin FDC three times daily (monotherapy and dual therapy)

\begin{tabular}{|c|c|c|c|c|c|c|}
\hline \multirow[t]{2}{*}{ Variable } & \multicolumn{3}{|c|}{$\begin{array}{l}\text { Repaglinide/metformin FDC } \\
\text { twice daily }\end{array}$} & \multicolumn{3}{|c|}{$\begin{array}{l}\text { Repaglinide/metformin FDC three } \\
\text { times daily }\end{array}$} \\
\hline & All $(n=187)$ & $M T(n=98)$ & DT $(n=89)$ & All $(n=187)$ & $M T(n=9 I)$ & DT $(n=96)$ \\
\hline Duration of type 2 diabetes & & 6.6 & 8.3 & & 5.6 & 8.9 \\
\hline Baseline $\mathrm{HbA} \mathrm{Ic}_{\mathrm{c}}$ & 8.4 & 8.7 & 8.2 & 8.3 & 8.4 & 8.2 \\
\hline$\Delta \mathrm{HbA}_{\mathrm{Ic}}$ & -0.95 & -1.27 & -0.62 & -1.08 & -1.48 & -0.69 \\
\hline$\% \mathrm{HbA}_{\mathrm{Ic}} \leq 6.5 \%$ & 25.4 & 29.0 & 21.4 & 25.8 & 35.3 & 17.2 \\
\hline$\% \mathrm{HbA}_{\mathrm{lc}} \leq 7.0 \%$ & 42.9 & $44.1^{* *}$ & 41.7 & 48.9 & 58.8 & 39.8 \\
\hline$\Delta \mathrm{FBG}$ & -18.4 & $-24.6 * *$ & -11.9 & -22.9 & -36.3 & -10.3 \\
\hline$\Delta$ Weight & $0.48^{*}$ & 1.7 & -0.9 & -0.33 & 0.7 & -1.2 \\
\hline Minor hypoglycemia (events/patient year) & 3.79 & 4.8 & 2.6 & 4.46 & 5.3 & 3.8 \\
\hline
\end{tabular}

$*_{p} \leq 0.05$ compared with three times daily dosing; ${ }^{*}{ }^{*} \mathrm{p} \leq 0.05$ compared with three times daily dosing patients on MT.

Abbreviations: MT, monotherapy; DT, dual therapy; $\Delta$, end of study change from baseline. 


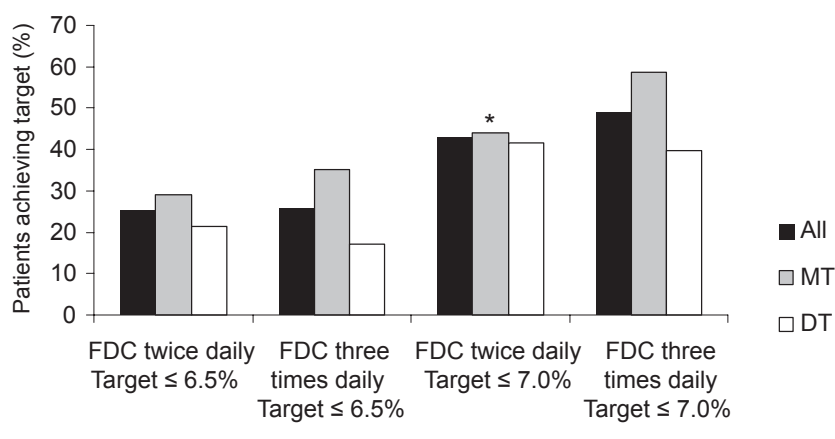

Figure 3 Percentage of patients treated with repaglinide/metformin FDC twice daily and three times daily achieving $\mathrm{HbA}_{\mathrm{Ic}}$ targets of $\leq 6.5 \%$ and $\leq 7.0 \%$. ${ }^{*} \mathrm{p} \leq 0.05$ compared with three times daily dosing patients on previous MT. ${ }^{35,37}$

Abbreviations: MT, previous OAD monotherapy; DT, previous OAD dual therapy.

compared with those on repaglinide/metformin FDC. When this was analyzed according to previous mono or dual therapy, the reduction in FBG was significantly greater in patients on rosiglitazone/metformin FDC twice daily who had previously been on monotherapy compared with those on repaglinide/ metformin FDC, but there was no significant difference in those who had previously been on dual therapy. ${ }^{36,38}$

Lipid measurements were reduced in patients on repaglinide/metformin FDC twice daily, while patients on rosiglitazone/metformin FDC had increases in lipid measurements; the differences between treatment groups were significant for total cholesterol, low-density lipoprotein and non-high-density lipoprotein, but not for triglycerides.
The subset analysis reflected these results. These results are reasonably consistent with previous studies. Metformin has been shown to reduce triglycerides and free fatty acids to the same extent as repaglinide, but to reduce total cholesterol, low-density lipoprotein and non-high-density lipoprotein to a greater extent. ${ }^{39} \mathrm{In}$ a study comparing the lipid responses of several oral hypogylcemic agents, including metformin, rosiglitazone and pioglitazone, metformin reduced total cholesterol at high doses, but the results for other lipid parameters were inconclusive. ${ }^{40}$ Pioglitazone had a more favorable effect overall on the lipid profile than rosiglitazone, a finding that has been confirmed in other clinical trials. ${ }^{41}$

There were no significant differences in change in weight between treatment groups or in the subset analysis. In the comparison of repaglinide/metformin FDC and rosiglitazone/metformin FDC, the rate of minor hypoglycemia was significantly higher in the repaglinide/metformin FDC group. However, more than $50 \%$ of these minor hypoglycemic episodes were reported by seven people. The rate of minor hypoglycemia was slightly higher in those previously on monotherapy compared with those on dual therapy in both treatment groups. ${ }^{36,38}$

The repaglinide/metformin FDC provides similar efficacy, including reductions in $\mathrm{HbA}_{1 \mathrm{c}}$, to rosiglitazone/metformin FDC, but there was a significant difference in changes in lipid profiles between groups; in those taking rosiglitazone, lipid profiles worsened but in those taking repaglinide, lipid profiles improved.

Table 2 Changes in $\mathrm{HbA}_{1 \mathrm{c}}$, FPG, weight and rate of minor hypoglycemia in patients on repaglinide/metformin FDC twice daily (monotherapy and dual therapy) and rosiglitazone/metformin FDC twice daily (monotherapy and dual therapy)

\begin{tabular}{|c|c|c|c|c|c|c|}
\hline \multirow[t]{2}{*}{ Variable } & \multicolumn{3}{|c|}{ Repaglinide/metformin FDC twice daily } & \multicolumn{3}{|c|}{ Rosiglitazone/metformin FDC twice daily } \\
\hline & All $(n=187)$ & $M T(n=98)$ & DT $(n=89)$ & All $(n=187)$ & $M T(n=97)$ & DT $(n=90)$ \\
\hline Baseline $\mathrm{HbA}_{\mathrm{lc}}$ & 8.4 & 8.7 & 8.2 & 8.4 & 8.7 & 8.2 \\
\hline$\Delta \mathrm{HbA}_{\mathrm{lc}}$ & -0.95 & -1.27 & -0.62 & -0.98 & -1.49 & -0.46 \\
\hline$\% \mathrm{HbA}_{\mathrm{Ic}} \leq 6.5 \%$ & 25.4 & 29.0 & 21.4 & 25.3 & 34.8 & 15.3 \\
\hline$\% \mathrm{HbA}_{\mathrm{Ic}} \leq 7.0 \%$ & 42.9 & 44.1 & 41.7 & 48.9 & 58.4 & 38.8 \\
\hline$\triangle \mathrm{FBG}$ & $-18.4^{*}$ & $-24.6 *$ & -11.9 & -35.6 & -49.1 & -21.8 \\
\hline$\Delta$ Weight & 0.48 & 1.7 & -0.9 & 0.31 & 1.2 & -0.6 \\
\hline \multicolumn{7}{|l|}{ Lipids } \\
\hline TC & $-1.3^{*}$ & $-1.7 *$ & $-1.0 * *$ & 18.3 & 20.4 & 15.7 \\
\hline LDL & $-2.6^{*}$ & $-2.3^{*}$ & $-3.3 * *$ & 9.6 & 10.6 & 8.3 \\
\hline HDL & $-0.2^{*}$ & $-0.3^{*}$ & $0.1 * *$ & 4.5 & 3.2 & 5.8 \\
\hline TG & -0.9 & -17.6 & $8.4^{* *}$ & 6.5 & 16.0 & 6.0 \\
\hline Non-HDL & $-1.3^{*}$ & $-1.7^{*}$ & $-0.9 * *$ & 12.8 & 15.5 & 9.8 \\
\hline $\begin{array}{l}\text { Minor hypoglycemia events } \\
\text { (events/patient year) }\end{array}$ & $3.79 *$ & 4.8 & 2.6 & 0.27 & 0.4 & 0.1 \\
\hline
\end{tabular}

${ }^{*} \mathrm{p} \leq 0.05$ repaglinide/metformin FDC monotherapy compared with rosiglitazone/metformin FDC monotherapy; $*$ p $\leq 0.05$ repaglinide/metformin FDC dual therapy compared with rosiglitazone/metformin FDC dual therapy.

Abbreviations: MT, monotherapy; DT, dual therapy; $\Delta$, end of study change from baseline. 


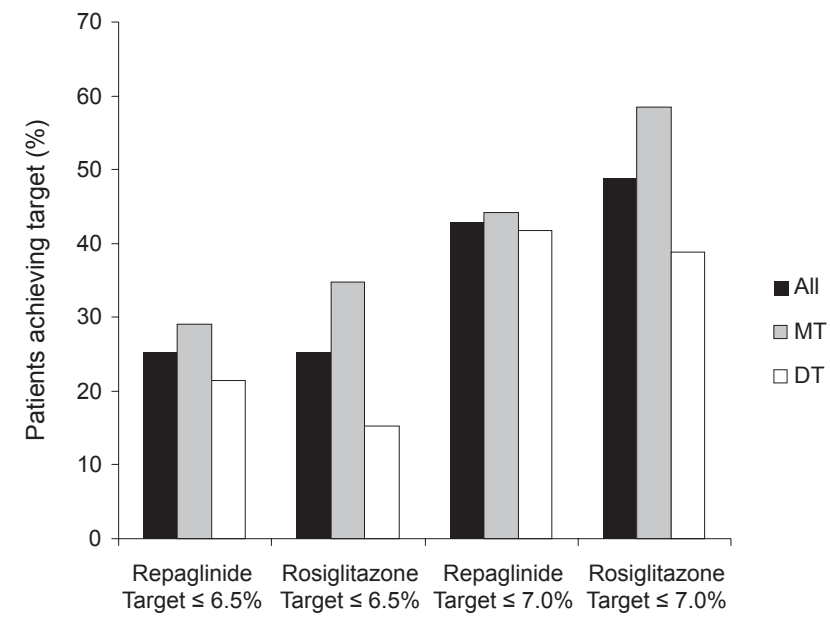

Figure 4 Percentage of patients treated with repaglinide/metformin FDC twice daily and rosiglitazone/metformin twice daily achieving $\mathrm{HbA}_{\mathrm{Ic}}$ targets of $\leq 6.5 \%$ and $\leq 7.0 \% .36 .38$ Abbreviations: MT, previous OAD monotherapy; DT, previous OAD dual therapy.

\section{Patient perspective}

Although treatment with more than one oral agent is essential in the management pathway of type 2 diabetes, adherence is an issue, particularly with elderly patients. Patients with type 2 diabetes who have switched to other FDCs (of glibenclamide and metformin) are more likely to comply with their therapy. ${ }^{13,14,42}$ This suggests that compliance is also likely to improve in patients taking repaglinide/metformin FDC compared with separate doses of each tablet. The combination of the two treatments may allow patients who experience side effects with metformin to reduce the dose of metformin without a loss of glycemic control.

\section{Conclusion}

Repaglinide, a rapid-acting insulin secretagogue, targets PPG, and metformin, an insulin sensitizer, targets FBG, the two key determinants of overall hyperglycemia. Repaglinide and metformin are frequently co-administered as separate formulations to manage hyperglycemia in patients with type 2 diabetes. Given that the effects of the two molecules are complementary and they may even act synergistically, the provision of both in a FDC is a logical step. The repaglinide/metformin FDC is effective in reducing $\mathrm{HbA}_{1 \mathrm{c}}$ and in achieving $\mathrm{HbA}_{1 \mathrm{c}}$ targets, whether it is taken twice or three times daily, meaning that patients can take fewer tablets less frequently than with dual therapy with individual tablets, thus reducing the risk of nonadherence associated with multiple tablets.

There is an increased drive in diabetes management towards early combination oral therapy to treat patients with type 2 diabetes to target to reduce the risk of vascular complications. As well as reducing $\mathrm{HbA}_{1 \mathrm{c}}$ to target, which has been shown to reduce the risk of these complications, repaglinide/metformin FDC, unlike the combination of rosiglitazone and metformin, improves the lipid profile, potentially further reducing patients cardiovascular risk profile.

With the increasing numbers of people with type 2 diabetes worldwide, and the need to manage this condition and its vascular complications effectively, repaglinide/metformin FDC provides physicians with an additional treatment option that reduces hyperglycemia with a good safety and tolerability profile, and the potential to improve adherence to therapy.

\section{Acknowledgments and disclosures}

This publication was supported by Novo Nordisk A/S (Bagsværd, Denmark) with editorial support from ESP Bioscience (Sandhurst, UK).

\section{References}

1. Rendell MS, Jovanovic L. Targeting postprandial hyperglycemia. Metabolism. 2006;55(9):1263-1281.

2. Monnier L, Lapinski H, Colette C. Contributions of fasting and postprandial plasma glucose increments to the overall diurnal hyperglycemia of type 2 diabetic patients: variations with increasing levels of $\mathrm{HbA(1c).} \mathrm{Diabetes} \mathrm{Care.} \mathrm{2003;26(3):881-885.}$

3. Intensive blood-glucose control with sulphonylureas or insulin compared with conventional treatment and risk of complications in patients with type 2 diabetes (UKPDS 33). UK Prospective Diabetes Study (UKPDS) Group. Lancet. 1998;352(9131):837-853.

4. Holman RR, Paul SK, Bethel MA, Matthews DR, Neil HA. 10-year follow-up of intensive glucose control in type 2 diabetes. N Engl J Med. 2008;359(15):1577-1589.

5. Stratton IM, Adler AI, Neil HA, et al. Association of glycaemia with macrovascular and microvascular complications of type 2 diabetes (UKPDS 35): prospective observational study. BMJ. 2000;321(7258): 405-412.

6. Gerstein HC, Miller ME, Byington RP, et al. Effects of intensive glucose lowering in type 2 diabetes. $N$ Engl J Med. 2008;358(24): 2545-2559.

7. Patel A, MacMahon S, Chalmers J, et al. Intensive blood glucose control and vascular outcomes in patients with type 2 diabetes. $N$ Engl $J$ Med. 2008;358(24):2560-2572.

8. Duckworth W, Abraira C, Moritz T, et al. Glucose control and vascular complications in veterans with type 2 diabetes. $N$ Engl J Med. 2009;360(2):129-139.

9. Skyler JS, Bergenstal R, Bonow RO, et al. Intensive glycemic control and the prevention of cardiovascular events: implications of the ACCORD, ADVANCE, and VA diabetes trials: a position statement of the American Diabetes Association and a scientific statement of the American College of Cardiology Foundation and the American Heart Association. Diabetes Care. 2009;32(1):187-192.

10. Effect of intensive blood-glucose control with metformin on complications in overweight patients with type 2 diabetes (UKPDS 34). UK Prospective Diabetes Study (UKPDS) Group. Lancet. 1998;352(9131): 854-865.

11. Rao AD, Kuhadiya N, Reynolds K, Fonseca VA. Is the combination of sulfonylureas and metformin associated with an increased risk of cardiovascular disease or all-cause mortality? A meta-analysis of observational studies. Diabetes Care. 2008;31(8):1672-1678.

12. Nathan DM, Buse JB, Davidson MB, et al. Medical management of hyperglycemia in type 2 diabetes: a consensus algorithm for the initiation and adjustment of therapy. Diabetes Care. 2008;31:1-11. 
13. Melikian C, White TJ, Vanderplas A, Dezii CM, Chang E. Adherence to oral antidiabetic therapy in a managed care organization: a comparison of monotherapy, combination therapy, and fixed-dose combination therapy. Clin Ther. 2002;24(3):460-467.

14. Blonde L, Wogen J, Kreilick C, Seymour AA. Greater reductions in A1C in type 2 diabetic patients new to therapy with glyburide/metformin tablets as compared to glyburide co-administered with metformin. Diabetes Obes Metab. 2003;5(6):424-431.

15. Gromada J, Dissing S, Kofod H, Frokjaer-Jensen J. Effects of the hypoglycaemic drugs repaglinide and glibenclamide on ATP-sensitive potassium-channels and cytosolic calcium levels in beta TC3 cells and rat pancreatic beta cells. Diabetologia. 1995;38(9):1025-1032.

16. Wolffenbuttel BH. Repaglinide - a new compound for the treatment of patients with type 2 diabetes. Neth J Med. 1999;55(5):229-234.

17. Fuhlendorff J, Rorsman P, Kofod H, et al. Stimulation of insulin release by repaglinide and glibenclamide involves both common and distinct processes. Diabetes. 1998;47(3):345-351.

18. Damsbo P, Clauson P, Marbury TC, Windfeld K. A double-blind randomized comparison of meal-related glycemic control by repaglinide and glyburide in well-controlled type 2 diabetic patients. Diabetes Care. 1999;22(5):789-794.

19. Marbury T, Huang WC, Strange P, Lebovitz H. Repaglinide versus glyburide: a one-year comparison trial. Diabetes Res Clin Pract. 1999; 43(3):155-166.

20. Landgraf R, Bilo HJ, Muller PG. A comparison of repaglinide and glibenclamide in the treatment of type 2 diabetic patients previously treated with sulphonylureas. Eur J Clin Pharmacol. 1999;55(3):165-171.

21. Van Gaal LF, Van Acker KL, De Leeuw IH. Repaglinide improves blood glucose control in sulphonylurea-naive type 2 diabetes. Diabetes Res Clin Pract. 2001;53(3):141-148.

22. Li J, Tian H, Li Q, et al. Improvement of insulin sensitivity and beta-cell function by nateglinide and repaglinide in type 2 diabetic patients $-\mathrm{a}$ randomized controlled double-blind and double-dummy multicentre clinical trial. Diabetes Obes Metab. 2007;9(4):558-565.

23. Rosenstock J, Hassman DR, Madder RD, et al. Repaglinide versus nateglinide monotherapy: a randomized, multicenter study. Diabetes Care. 2004;27(6):1265-1270.

24. Bailey CJ, Turner RC. Metformin. N Engl J Med. 1996;334(9): 574-579.

25. Johansen K. Efficacy of metformin in the treatment of NIDDM. Metaanalysis. Diabetes Care. 1999;22(1):33-37.

26. Inzucchi SE, Maggs DG, Spollett GR, et al. Efficacy and metabolic effects of metformin and troglitazone in type II diabetes mellitus. $N E n g l$ J Med. 1998;338(13):867-872.

27. Saenz A, Fernandez-Esteban I, Mataix A, Ausejo M, Roque M, Moher D. Metformin monotherapy for type 2 diabetes mellitus. Cochrane Database Syst Rev. 2005(3):CD002966.

28. Rudovich NN, Leyck Dieken MG, Rochlitz H, Pfeiffer AF. Enhancement of early- and late-phase insulin secretion and insulin sensitivity by the combination of repaglinide and metformin in type 2 diabetes mellitus. Exp Clin Endocrinol Diabetes. 2004;112(7):395-400.

29. Moses R, Slobodniuk R, Boyages S, et al. Effect of repaglinide addition to metformin monotherapy on glycemic control in patients with type 2 diabetes. Diabetes Care. 1999;22(1):119-124.
30. Moses RG. Achieving glycosylated hemoglobin targets using the combination of repaglinide and metformin in type 2 diabetes: a reanalysis of earlier data in terms of current targets. Clin Ther. 2008;30(3):552-554.

31. Reboussin DM, Goff DC Jr, Lipkin EW, et al. The combination oral and nutritional treatment of late-onset diabetes mellitus (CONTROL DM) trial results. Diabet Med. 2004;21(10):1082-1089.

32. Raskin P, Klaff L, McGill J, et al. Efficacy and safety of combination therapy: repaglinide plus metformin versus nateglinide plus metformin. Diabetes Care. 2003;26(7):2063-2068.

33. Hoelscher D, Chu PL, Lyness W. Fixed-dose combination tablet of repaglinide and metformin is bioequivalent to concomitantly administered individual tablets of repaglinide and metformin: randomized, single-blind, three-period crossover study in healthy subjects. Clin Drug Investig. 2008;28(9):573-582.

34. Reilley S, Chang C-T, Lyness W. Single-dose pharmacokinetics of a repaglinide/metformin fixed-dose combination tablet in fasted and fed conditions. 68th Scientific Session of the ADA. June 6-10, 2008; San Francisco, CA, USA. Abstr no. 2133-P0.

35. Raskin P, Hang Y, Lyness W. Twice-daily and thrice-daily dosing of a repaglinide/metformin fixed-dose combination tablet provide similar glycemic control. 68th Scientific Session of the ADA. June 6-10, 2008; San Francisco, CA, USA. Abstr no. 2153-P0.

36. Raskin P, Hang Y, Lyness W. Twice-daily dosing of a repaglinide/ metformin fixed-dose combination tablet provides glycemic control similar to a rosiglitazone/metformin fixed-dose combination tablet. 68th Scientific Session of the ADA. June 6-10, 2008; San Francisco, CA, USA. Abstr no. 2154-P0.

37. Fordan S, Hang Y, Lyness W, Raskin P. Twice-daily vs thrice-daily dosing of a repaglinide/metformin fixed-dose combination tablet in T2DM subjects previously treated with monotherapy vs dual therapy. 68th Scientific Session of the ADA. June 6-10, 2008; San Francisco, CA, USA. Abstr no. 2155-P0.

38. Rhee C, Hang Y, Lyness W, Raskin P. Repaglinide/metformin fixed-dose combination tablet vs rosiglitazone/metformin fixed-dose combination tablet in T2DM subjects evaluated by prior OAD treatment regimen. 68th Scientific Session of the ADA. June 6-10, 2008; San Francisco, CA, USA. Abstr no. 2125-P0.

39. Lund SS, Tarnow L, Frandsen M, et al. Impact of metformin versus the prandial insulin secretagogue, repaglinide, on fasting and postprandial glucose and lipid responses in non-obese patients with type 2 diabetes. Eur J Endocrinol. 2008;158(1):35-46.

40. Buse JB, Tan MH, Prince MJ, Erickson PP. The effects of oral antihyperglycaemic medications on serum lipid profiles in patients with type 2 diabetes. Diabetes Obes Metab. 2004;6(2):133-156.

41. Deeg MA, Tan MH. Pioglitazone versus rosiglitazone: effects on lipids, lipoproteins, and apolipoproteins in head-to-head randomized clinical studies. PPAR Res. 2008;2008:520465.

42. Dailey GE. Glyburide/metformin tablets: a new therapeutic option for the management of Type 2 diabetes. Expert Opin Pharmacother. 2003;4(8):1417-1430.

43. Raskin P. Oral combination therapy: repaglinide plus metformin for treatment of type 2 diabetes. Diabetes Obes Metab. 2008;10(12):1167-1177.

Diabetes, Metabolic Syndrome and Obesity: Targets and Therapy

Dovepress

\section{Publish your work in this journal}

Diabetes, Metabolic Syndrome and Obesity: Targets and Therapy is an international, peer-reviewed open-access journal committed to the rapid publication of the latest laboratory and clinical findings in the fields of diabetes, metabolic syndrome and obesity research Original research, review, case reports, hypothesis formation, expert opinion and commentaries are all considered for publication. The manuscript management system is completely online and includes a very quick and fair peer-review system, which is all easy to use. Visit http://www.dovepress.com/testimonials.php to read real quotes from published authors. 